\title{
Across Edges: Art to Cartography; One Landscape to the Next
}

\author{
Darren Sears \\ Artist/Cartographer, represented by Hang Art Gallery (San Francisco, USA), darren@darrensears.com
}

\begin{abstract}
Maps have the empowering effect of placing the "world at your fingertips," compressing portions of it into a more "knowable" form. I find that some places have this map-like character even in real life - natural environments that are sliced by sharp, unexpected edges and contrasts into more accessible and digestible fragments. Over the years I have explored creating maps that heighten these places' compressed quality but also preserve their immersive aspect.
\end{abstract}

This search led me first to the field of landscape architecture, and then into two dimensions after I realized that creating these idealized places out in real world was mostly a fantasy. I began piecing together travel photographs into abstract photomontages, later reinterpreted in oil paints, that sharpen natural edges and contrasts to depict imaginary places. I then transitioned to watercolors, and toward depicting places not quite as imaginary, using the same fractured style to combine travel-inspired landscapes with bird's-eye views.

Finding the task of painting the individual fragments less engaging than the process of shaping them into compositions, I came to think of these works as maps in terms of both theory and process-in emphasizing the spatial relationships between scenes rather than the individual scenes themselves. My motivation for creating these maps has expanded beyond personal fulfilment to include conveying the fragility of the natural remnants and contrasts that captivate me.

Keywords: artistic cartography, map art, cognitive geography, ecology, landscape

\section{Introduction}

I am attracted to maps largely for their empowering effect of condensing pieces of the real world down into a more "knowable" form. In downsizing the multiple facets of a place and sharpening the contrasts between them, maps emphasize the edges and adjacencies of those facets. It is experiencing a landscape's edge and then a different environment beyond it that makes that landscape comprehensible and meaningful to me, just as darkness gives meaning to light.

Some real-world places-islands and landscape patchworks of various kinds with well-defined edges around or within them - have this map-like character even before they are distilled onto paper. I find these "lived maps" empowering in their own way: representing landscape contrasts from above on 2-D maps might accentuate the real thing, but those representations lack the power of immersion. What sort of map might further compress the "lived" version while preserving an element of the real-world experience that is crucial to its impact? The search for a means of expressing my ultimately spatial rather than scenic way of viewing the world has been a multi-year exploration across the boundaries of art, design, and cartography.

\section{Lived Maps}

My concept of "lived maps" applies particularly to natural environments. The edges themselves might be either natural or human-made but the landscapes defined by those edges, being not of our creation, inherently take special effort to absorb (to "know"). Human-made edges, where developed land abuts or (especially) hems in remnant natural features or native ecosystems, have the effect of humanizing "wilderness" areas that were once inaccessible or dominating. Natural edges are humanizing too though in a less literal sense, dividing nature into more digestible pieces including small water-defined islands, geological islands like isolated mountains and depressions, ecological islands like desert oases, and parallel ecological zones along coastlines.

A few other natural-edge examples are particularly captivating to me because they represent not only this subdividing of the natural world but also seemingly reallife "compression" of natural phenomena. One example is steep precipitation and temperature gradients climbing mountains or straddling the windward and leeward sides of a mountain range. These gradients compress levels of climatic and ecological diversity usually associated with entire continents into surprisingly small areas; this can be seen particularly dramatically on tropical islands where even relatively minimal elevation changes often produce striking wet-dry contrasts. Another example, geological rather than ecological, involves small volcanic cones and craters that can be explored quickly and safely. The cones are formally distinct from the surrounding landscape and the craters are distinct from everything beyond them. But in a similar way to sharp climatic gradients, these features 
seem to compress and humanize entities usually thought of as overwhelming in scale or force.

\section{Early Exploration}

Human-created edges did not capture much of my attention early on, but my fascination with the ecological and geological kind began in childhood. Reading The Little Prince and growing up in the monotonous (at least to me at the time) landscape of Ohio probably had some influence. Starting as a teenager and college student I was lucky to visit a number of examples in the Hawaiian and Galápagos Islands, the American West, East Africa, Peru, and Madagascar. Witnessing these places' surreal wet-dry contrasts and volcanic landforms, and feeling unfulfilled when I could not explore them from one end to the other, further demonstrated that there was something vitally gratifying about these "world-shrinking" features. I began accentuating or inventing them in semi-abstract paintings.

Along with a variety of geography- and design-related interests, my urge to engage and accentuate these lived maps drew me to the field of landscape architecture. I believed its aim of bringing order and clarity to the environment would allow me to shape experiences of natural contrasts - or to create abstract, idealized versions of them - in the physical world. The field turned out to be a good fit in many ways, and a few projects in graduate school and early in design practice did allow me to apply this idiosyncratic focus. But in the longer term those opportunities were rare and never went beyond drawings. I realized I would need to satisfy this particular passion not only in two dimensions but outside the design profession.

\section{Fracturing}

Inspired by some of my early artwork, I began digitally piecing together travel photographs into photomontages that sharpen the boundaries between and around landscapes of a particular character (Figs. $1 \& 2$ ). These "fractured" compositions depict lived maps that are hypothetical, made up of real scenes that may be continents apart, but I would like to think they could really exist. Since the cutting-and-pasting process directly embodies the aim of abstracting and sharpening landscape boundaries - "architecturalizing" nature by slicing it up with straight lines-I rarely made an effort to merge fragments together. However, I did soften or obscure portions of the edges to fool the eye into subconsciously thinking that these places are real.

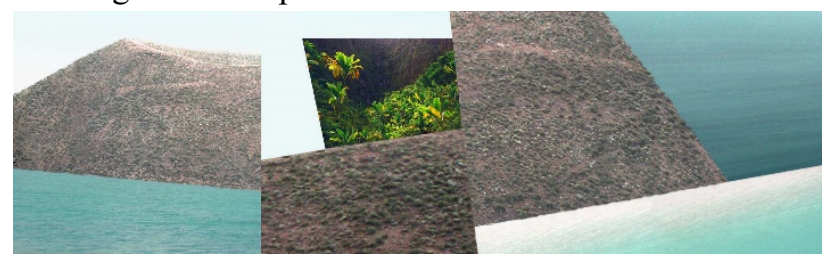

Figure 1. Interior (photomontage), accentuating three kinds of "lived maps" - an oasis, an accessible volcano, and a small island. The volcano, fractured into three pieces and further set apart by water (the real-life cone is not an island), was photographed in the Valley of the Volcanoes in Peru. The oasis image is from Hanakapiai Falls on Kauai.

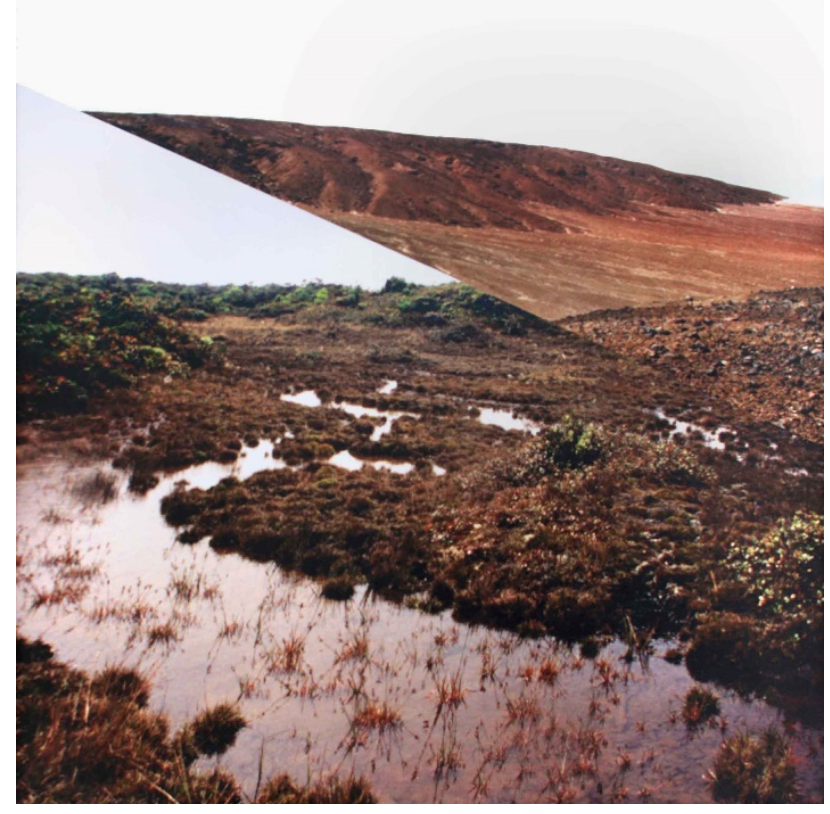

Figure 2. High Desert (photomontage), depicting an imaginary and improbably sharp contrast between lowland desert and highland bog. The source images are from Death Valley in California (top right) and the Alakai Swamp on Kauai. Despite the images' similar hues, obscuring part of the edge, these are respectively the driest and wettest places in the United States.

A few years into the photomontage experiments, wanting to go up in scale beyond what the low resolution of the source photographs allowed, and desiring more flexibility to adjust the content of the individual scenes and the sharpness of the edges, I began reinterpreting the photomontages in oil paints (Figs. $3 \& 4$ ).

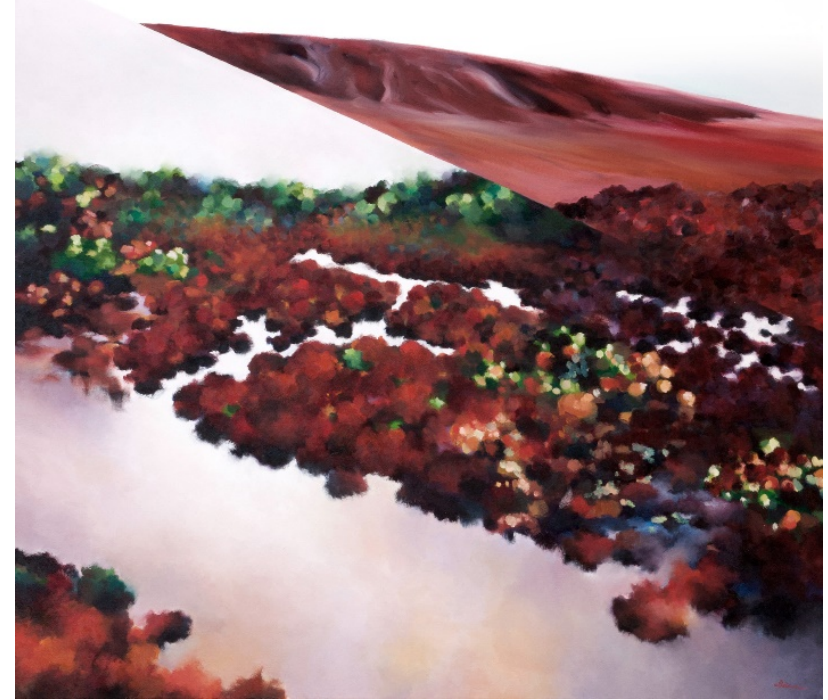

Figure 3. High Desert, the painted version (oil on canvas, 48 "x 48 "). 


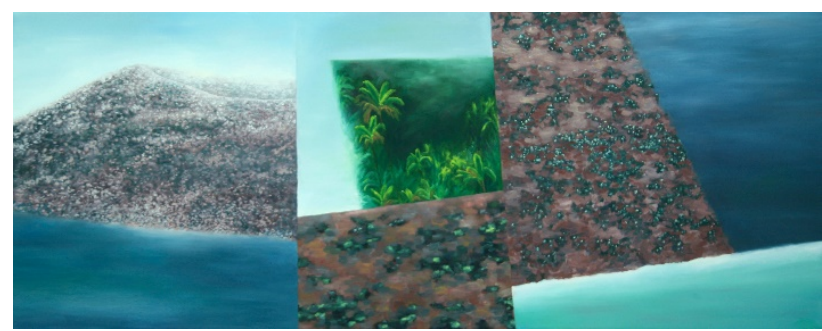

Figure 4. Interior, the painted version (oil on canvas, 26"x66").

\section{Precision}

Having scientific as much as artistic inclinations, I had been drawn to landscape architecture not only by the prospect of realizing my visions in real-life landscapes but by the analysis, problem-solving, and precision that would be integral to the process. The photomontages and oil paintings drew on those only minimally, and so even though the results would still never be habitable spaces, I tried approaching my lived map idealizations more like design projects.

This took the form of a detour away from the fractured style into aerial/plan views of imaginary islands and volcanic landscapes, only loosely inspired by real places, and from oil to watercolor because I found the latter to be better for representing natural textures. I partially overlaid the watercolors with contour lines and sectional profiles drawn on or etched into plexiglass, or with plexiglass layered into translucent topographical models (Figs. 5 \& $6)$.

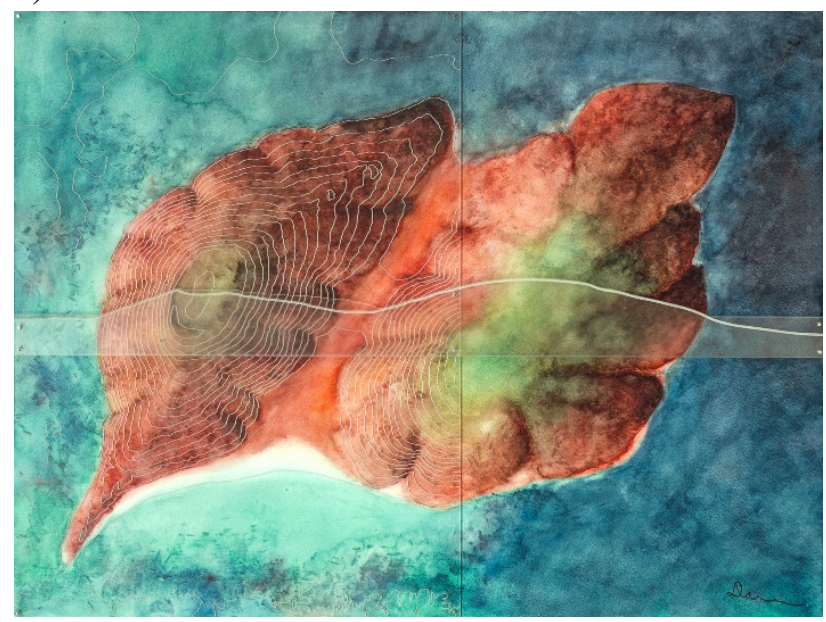

Figure 5. Seabiscuit Island (watercolor on paper overlaid with laser-etched plexiglass, mounted on wood panel, 15"x20"). This imaginary island is my idea of how the place pictured in High Desert (Figs. 2 \& 3), with its dramatic rainfall gradient between lowlands and highlands, might look from the air.

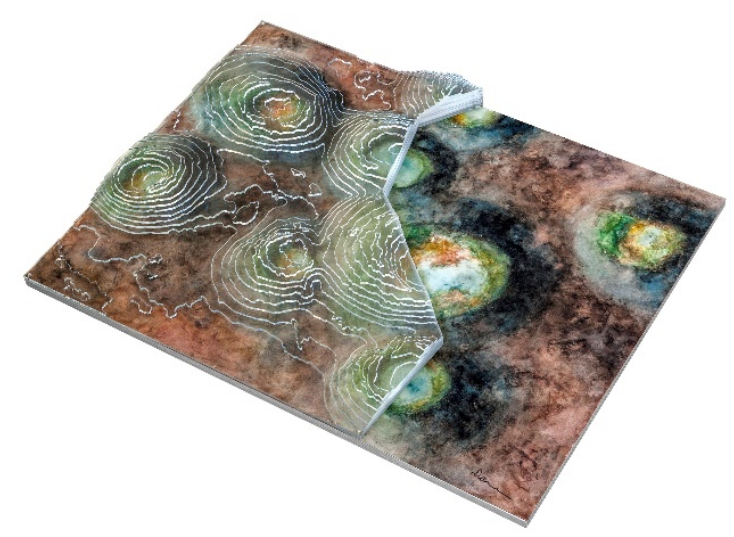

Figure 6. Windows (watercolor on paper overlaid with layered plexiglass, mounted on wood panel, 15"x20"x1") - an imaginary Iceland-inspired landscape of volcanoes and hot springs.

In place of the architecturalizing provided by compositional fragmentation, I integrated designed elements into the places themselves which range from paths and recreational spaces to actual structures like boardwalks and the occasional building. These "interventions" culminated in my first forays into depicting human-created edges, an interest that began in design school where it was considered more relevant than the natural-edge passion. In several works I depict volcanic landscapes as urban parks surrounded by city streets, reinforcing geological edges with the urban edge to further "domesticate" the landforms (Fig. 7).

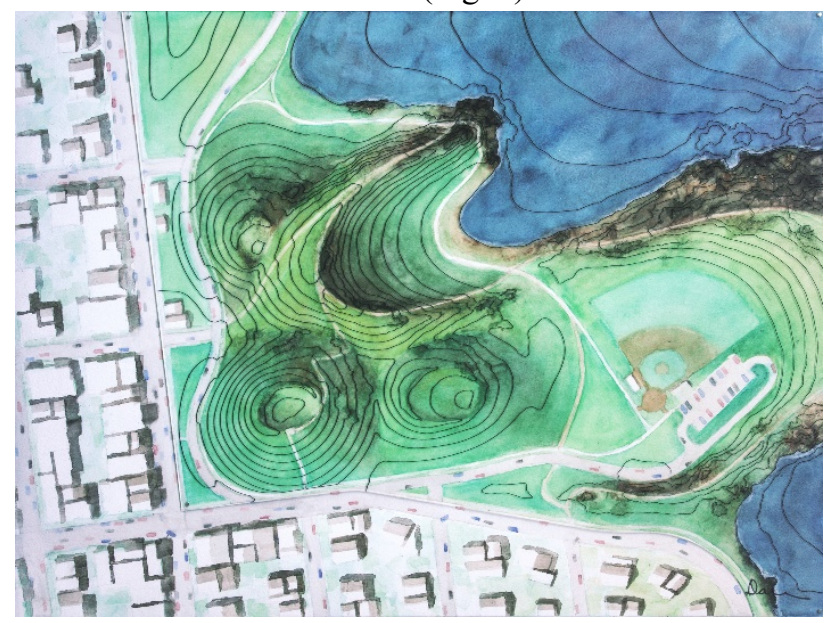

Figure 7. Community Crater Cluster (watercolor on paper overlaid with oil pen on plexiglass, mounted on wood panel, 15 "x20"). This depiction of miniature volcanoes in an urban park was inspired by a dream I had after visiting similar (but much less sharp) juxtapositions in Iceland.

\section{Synthesis}

But this detour into aerial-focused representations sacrificed the immersive quality of the fractured works, and so ultimately I arrived at a mix of the two approaches (Figs. $8 \&$ 9). Sticking with watercolors, in each work I began integrating landscape views into the aerial view, orienting the former based on the direction of the perspective in relation to the latter rather than necessarily right-side up. Thus many of the compositions can in theory be oriented multiple ways. The landscape pieces are still 
mostly translations of my own photographs, while the aerials draw to varying degrees on satellite imagery. Unlike the oil paintings, based on photomontages that already existed, these compositions have no digital precursors.

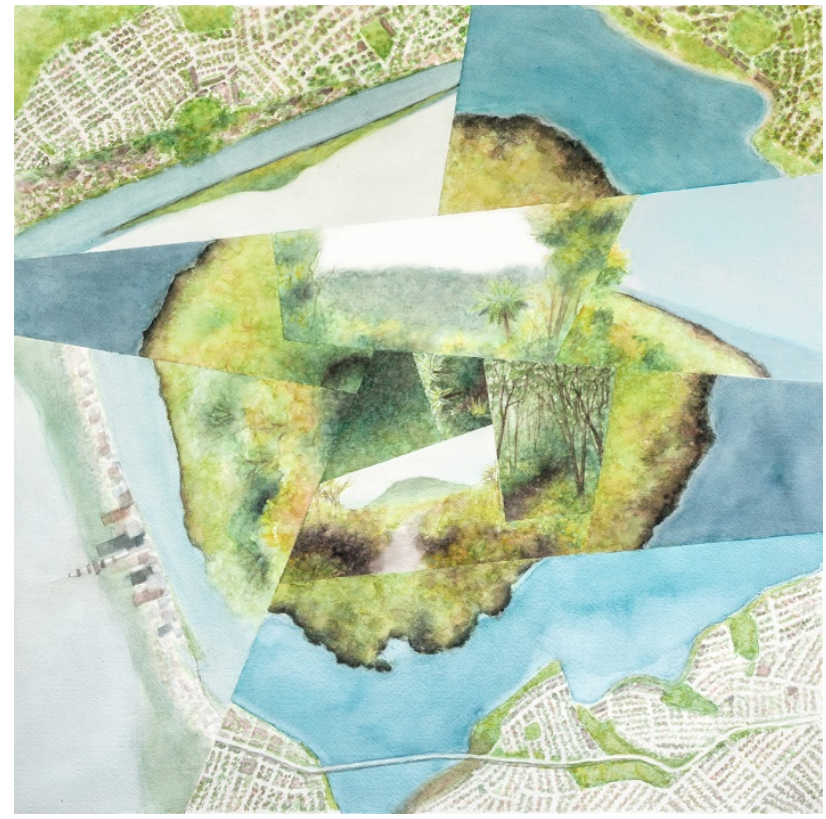

Figure 8. Harbour Island (watercolor on paper, 18"x18"), inspired by Rangitoto, a volcanic island a short boat ride from downtown Auckland, New Zealand. The work layers and accentuates multiple lived maps - a moisture gradient from sea level to summit, a small and accessible volcano, and an urban"wild" contrast.

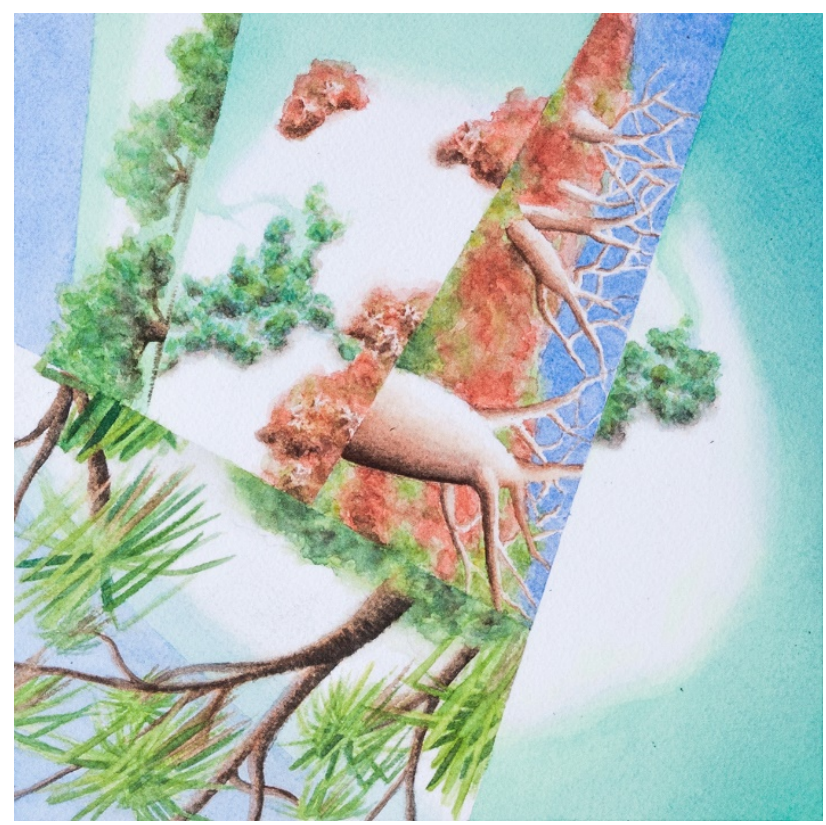

Figure 9. Pearl Isle (watercolor on paper, 8" $\mathrm{x} 8$ "), an imaginary island combining elements of northwest Australia. (In this case the individual scenes are invented as well as the overall place.)

Since the landscape fragments end up fracturing and distorting the aerials and forcing some ambiguity into them, these most recent works do lack the spatial and topographical precision of the purely bird's-eye series. But they have begun to incorporate many more fragments on average, and the very process of shaping and arranging those fragments to convey the spatial experience that I have in mind-while creating an aesthetically pleasing layout - compensates in a way by requiring a similar type of problem-solving (Figs. $10 \& 11$ ).

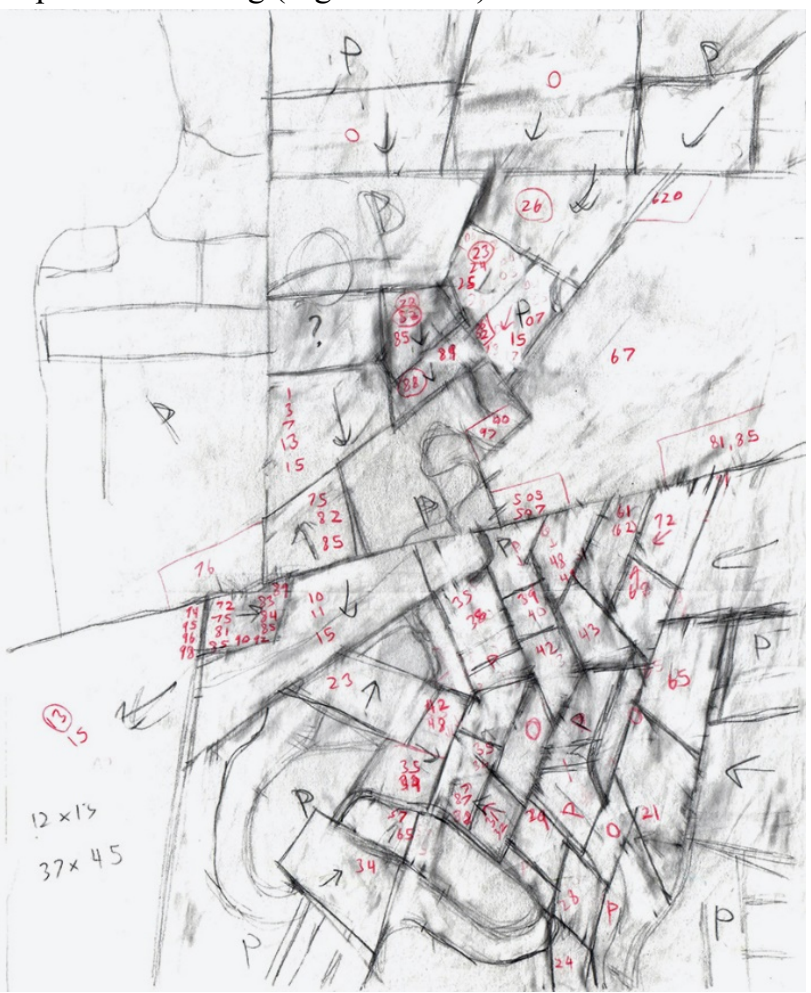

Figure 10. Process sketch resulting in Peaks (Fig. 11).

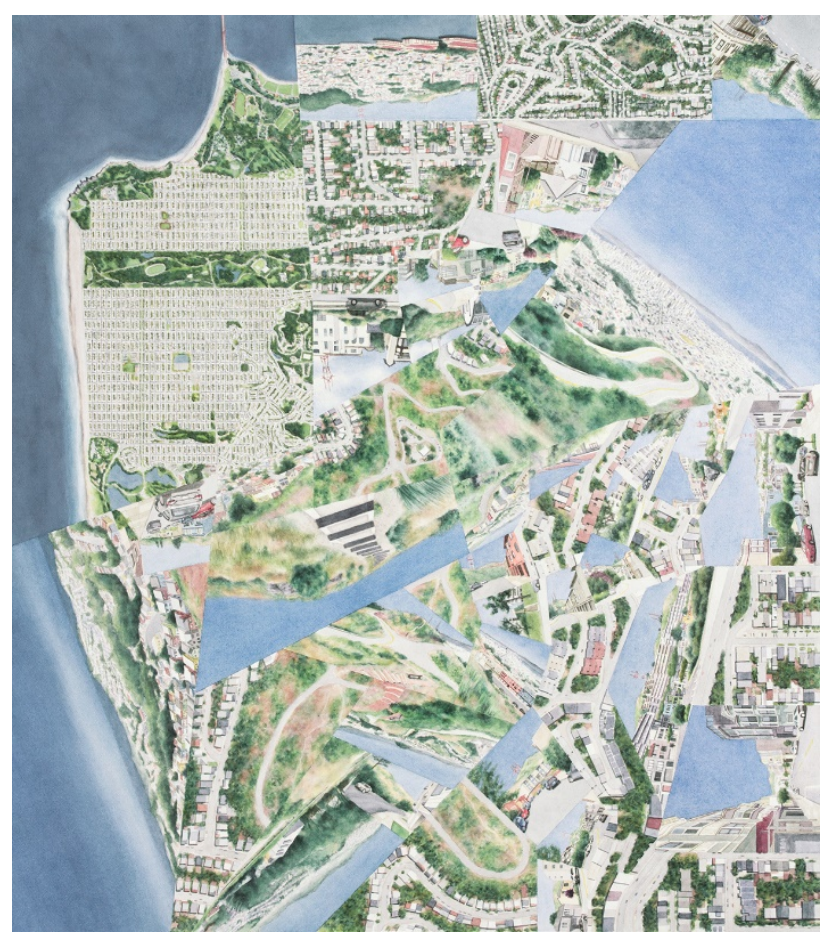

Figure 11. Peaks (watercolor on paper, 42"x37"). This work is inspired by the landscape of San Francisco's Twin Peaks - far from pristine but raw and reasonably natural in character-and its juxtaposition with the surrounding city. 
In fact the task of translating each fragment from photography to paint, regardless of how literal that translation is, feels mostly like just a job to get out of the way-secondary to the process of structuring (i.e. designing) the overall composition. So I gradually came to think of the fractured works, in all media but particularly the watercolors given their greater number of facets, as fundamentally cartographic: in terms of both theory and process they emphasize the spatial relationships between scenes rather than the individual scenes themselves. The process of designing those relationships is, essentially, drawing the map.

I have not only started describing the works as maps instead of paintings but also instead of artwork generally. True, the definitions of "map" and "artwork" are increasingly wide and overlapping, spanning objective and subjective, analytical and creative, and real and imagined. Defining a work that would easily be considered art by the average viewer, in terms of both style and medium, instead as a map might come across as academic or confusing. But I have found the cartographic framing to be essential in clarifying my vision and approach.

To date, most of the fractured watercolors draw on my recent travels in South America and Australia/New Zealand. Some of the compositions, as with the photomontages and oils, piece together scenes that are many miles apart in real life. But the more recent works tend to be accentuations of real landscape contrasts, of both the natural and human-made kind (Figs. $12 \& 13$ ).

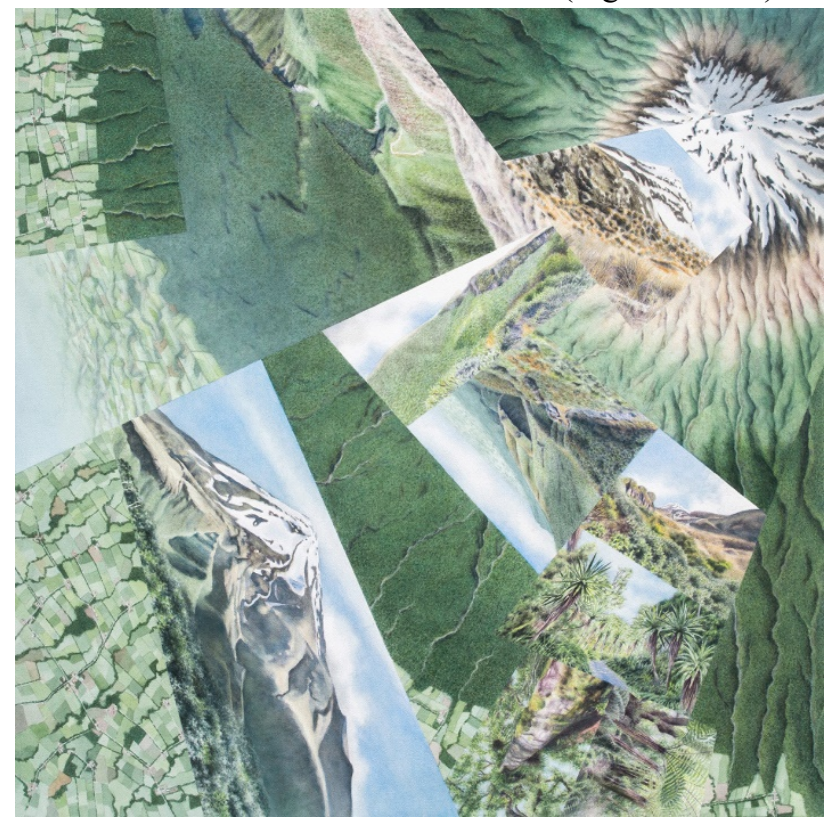

Figure 12. Cone (watercolor on paper, 36"x36"). Mt. Taranaki in New Zealand is an ideal example of a lived map: the outline of the preserved forest at its base forms a nearly perfect circle within the surrounding farmland, and the ecological zonation from rainforest to alpine forms neat concentric circles within. Given that strikingly clear pattern I avoided any significant distortion of the aerial (and I had no need to accentuate it), though the landscape fragments compress my experience of hiking through those zones. The work covers roughly one quadrant of the mountain.

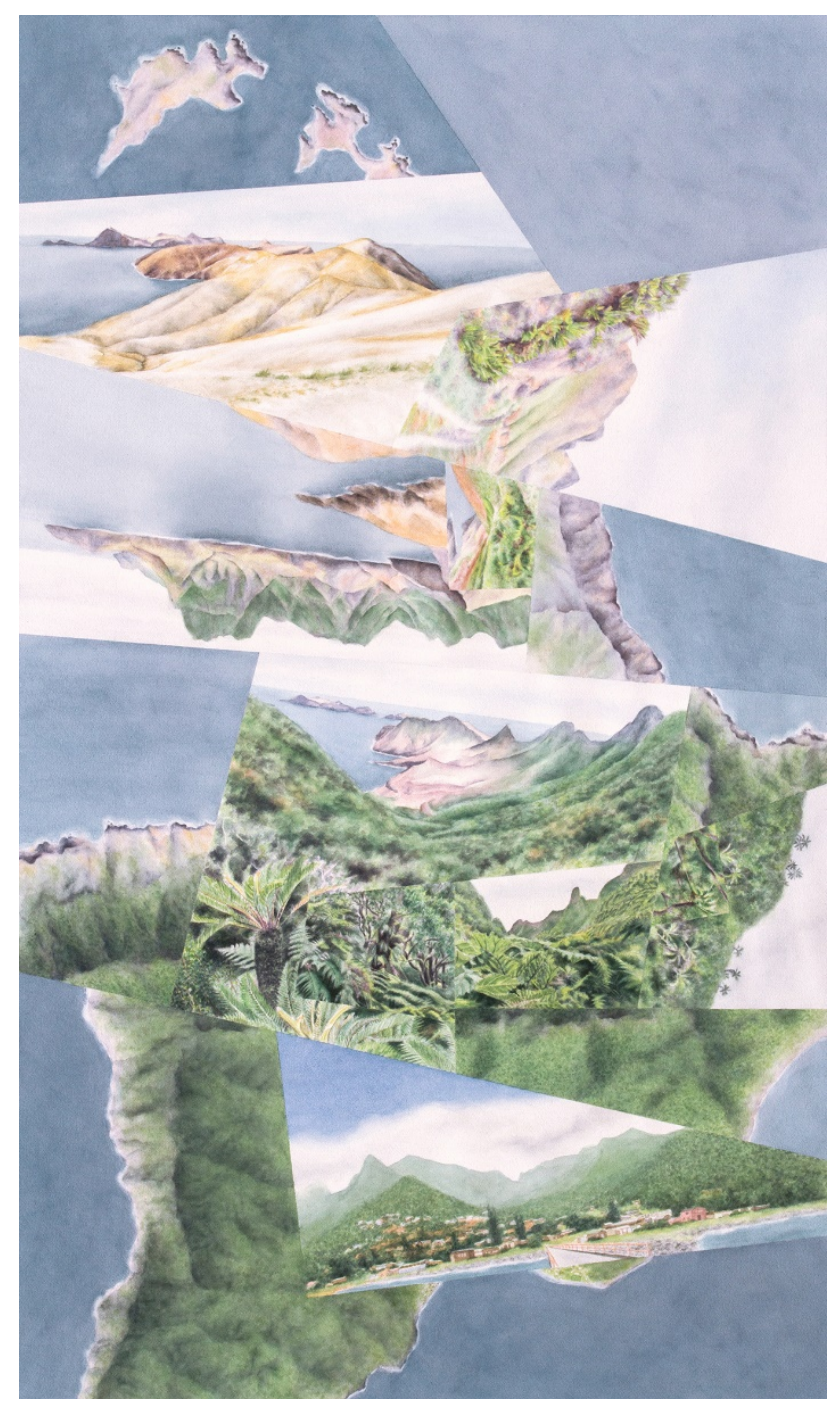

Figure 13. Mirador (watercolor on paper, 48"x28"), inspired by a dramatic wet-dry gradient across Robinson Crusoe Island off the central coast of Chile.

I have increasingly focused on idealizations of real sites partly because the most powerful lived maps are those in the actual world rather than a hypothetical one. Additionally the challenge of fitting my personal, idealized experience of a place into real-world geography, balancing distortion of that geography with preserving its original impact, is more interesting than being free to invent that geography from scratch-similar to the advantage of designing with site constraints versus a blank slate in a landscape architecture project. These more reality-based compositions usually depict a particular linear and directional "journey" through a place, along an abstracted version of the route that I travelled on-site, leading the eye from one view to the next (Fig. 14).

\section{Worldviews}

Though I call these works maps, that term is not very descriptive and can also be misleading given its traditional association with purely bird's-eye views. There is usually no way to avoid long explanations, so I have begun supplementing "maps" with another term-worldviewsno less opaque but more descriptive and poetic. 


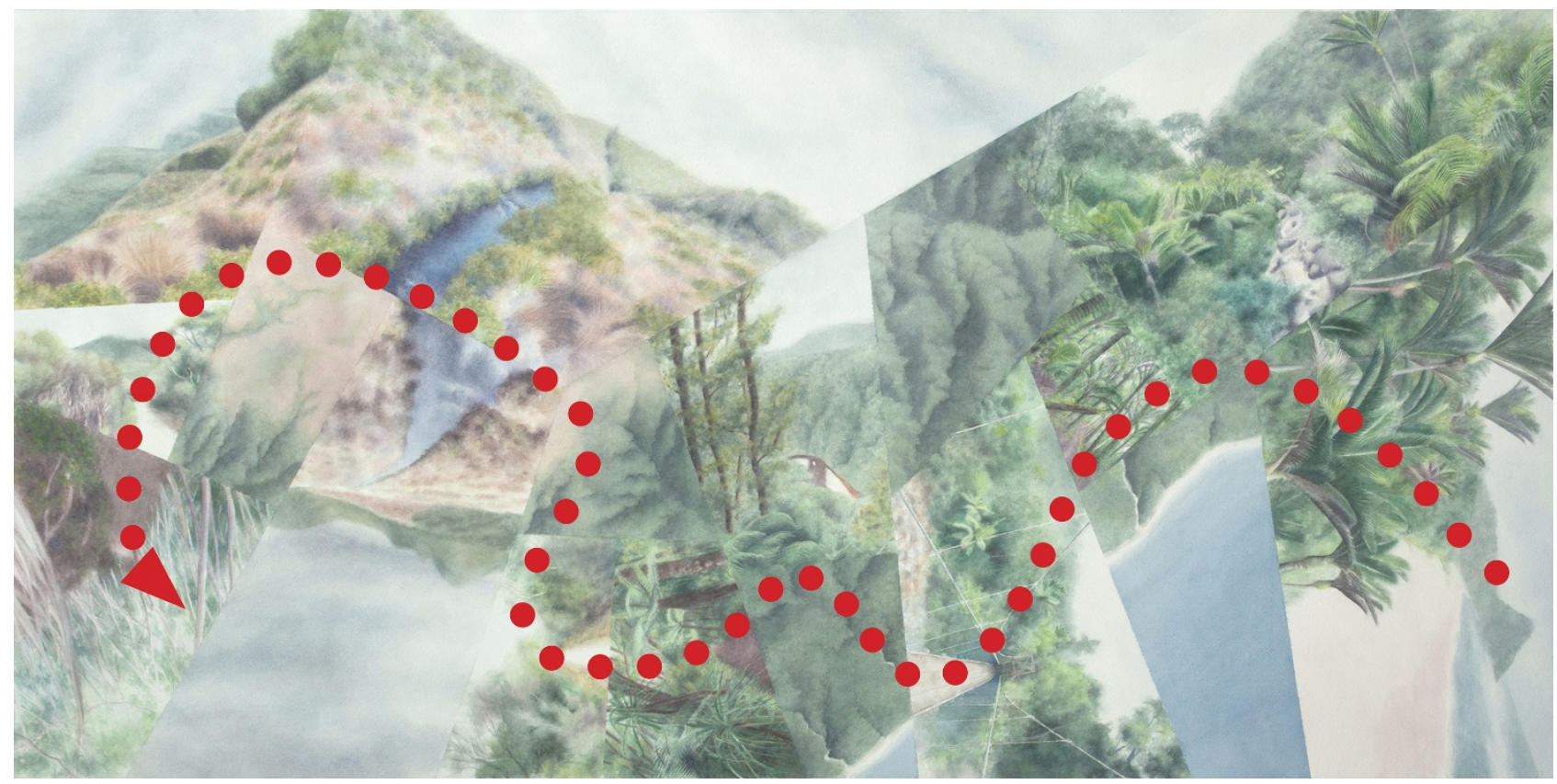

It has been suggested to me that the purely aerial works are maps, but that the fractured works - in drawing the viewer into the place-are worlds. To me the fractured works are both. Worlds does more vividly highlight their immersiveness as well as the characteristic that I believe makes them maps - their omniscient quality. Each work depicts a complete, multi-faceted "world at your fingertips," compressed into a single view, explored simultaneously from above and within: an empowering and all-encompassing experience of a place (Figs. $15 \&$ 16). As I first explored in the photomontages, the edges of those facets melt away in places to momentarily reveal a single, seamless impression of that multi-dimensional world. The standard meaning of the term worldview applies as well: it references my particular way of viewing the world in map form-in spatial rather than scenic terms - whether I am distilling it onto paper or exploring it on foot.

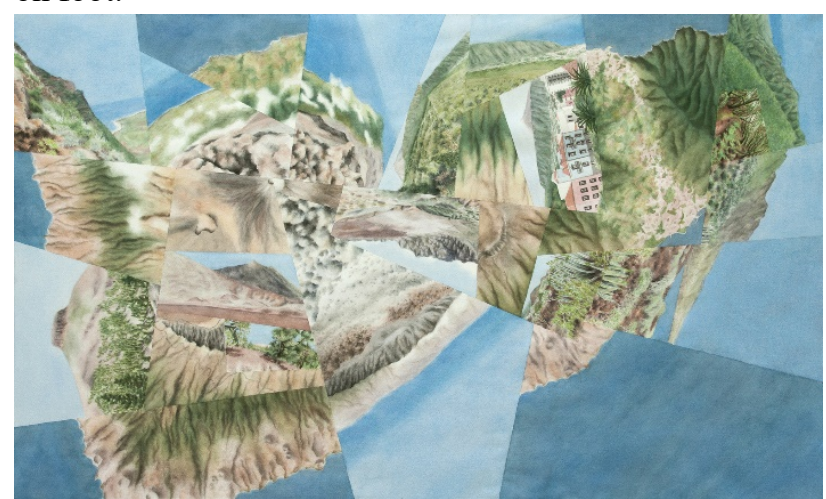

Figure 15. Reveal (watercolor on paper, 30"x50"), depicting the "island-continent" of Tenerife in the Canaries. This view on a clear day "reveals" lowland and alpine desert, pine forest, and rainforest landscapes that are compressed together into this selfcontained world but that at the same time feel worlds apart.

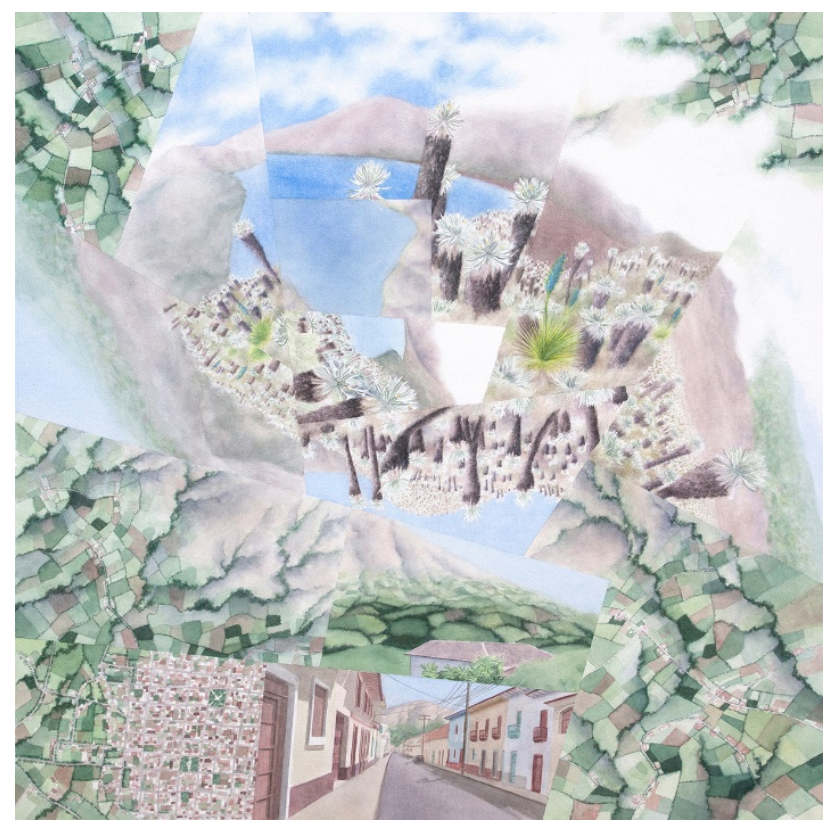

Figure 16. Lagoon (watercolor on paper, 36"x36”). This work accentuates the juxtaposition of surreal páramo (alpine moorland) landscape and "civilization" in the vicinity of El Angel Ecological Reserve, Ecuador.

My captivation with sharp and unexpected real-world contrasts, and the evolution of the fracturing method as a way to intensify those lived maps without losing their "lived" quality, is part of a more basic impulse to manage complexity. The sense of empowerment drawing me to experience and depict these places by definition requires embracing environmental complexity to a degree because it creates those contrasts in the first place. But compressing that complexity into an even more striking and digestible form on a small 2-D surface requires organizing it into a 
clear structure of contrasts and relationships. I have found this structuring aspect to be a form of design, a problemsolving challenge taking the place of a more precisionoriented approach that the abstract fractured style does not allow. More broadly though, harnessing complexityfinding a balance between embracing and organizing it-I consider to be a cartographic endeavor central to the aim and process of creating the worldviews.

This drive to manage complexity came about to satisfy an emotional need, probably part of a grasping for control over life in general. (Embracing and organizing geographical complexity could be analogous, respectively, to wanting to keep all my options available while craving structure and predictability.) But over the past few years my motivation has widened to include an environmental stewardship component as well as a personal one. It is another reason for my shift toward depicting real places: my attraction to environmental edges is linked to a growing distress at the fragility of the real landscapes they define. Small and rare pieces of nature, whether their edges are ecologically-determined or are human-created to begin with, tend to be especially vulnerable to climate change and other environmental threats. Most notably, many complex ecological zonation patterns are generated by finely-tuned climatic conditions that I doubt will stay that way for long (Fig. 17).

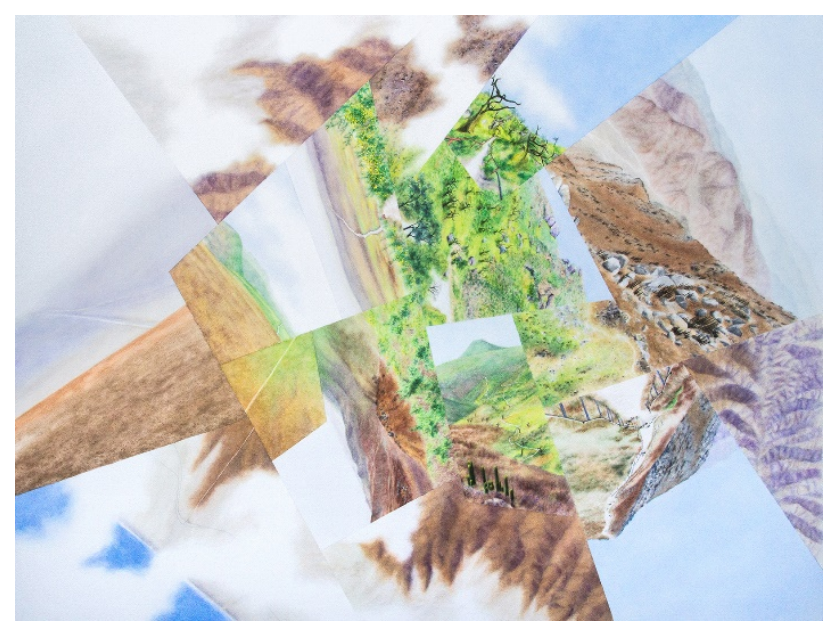

I recognize the paradox in seeking a firmer psychological grasp over these precarious environments - especially if human activity explains why they are already tiny and distinct-by further compressing their scales and sharpening their edges, while at the same time wishing they had more breathing room to persist. But I have decided to embrace this tension, seeing my yearning to have the "world at my fingertips" as part of a protective impulse (Fig. 18).

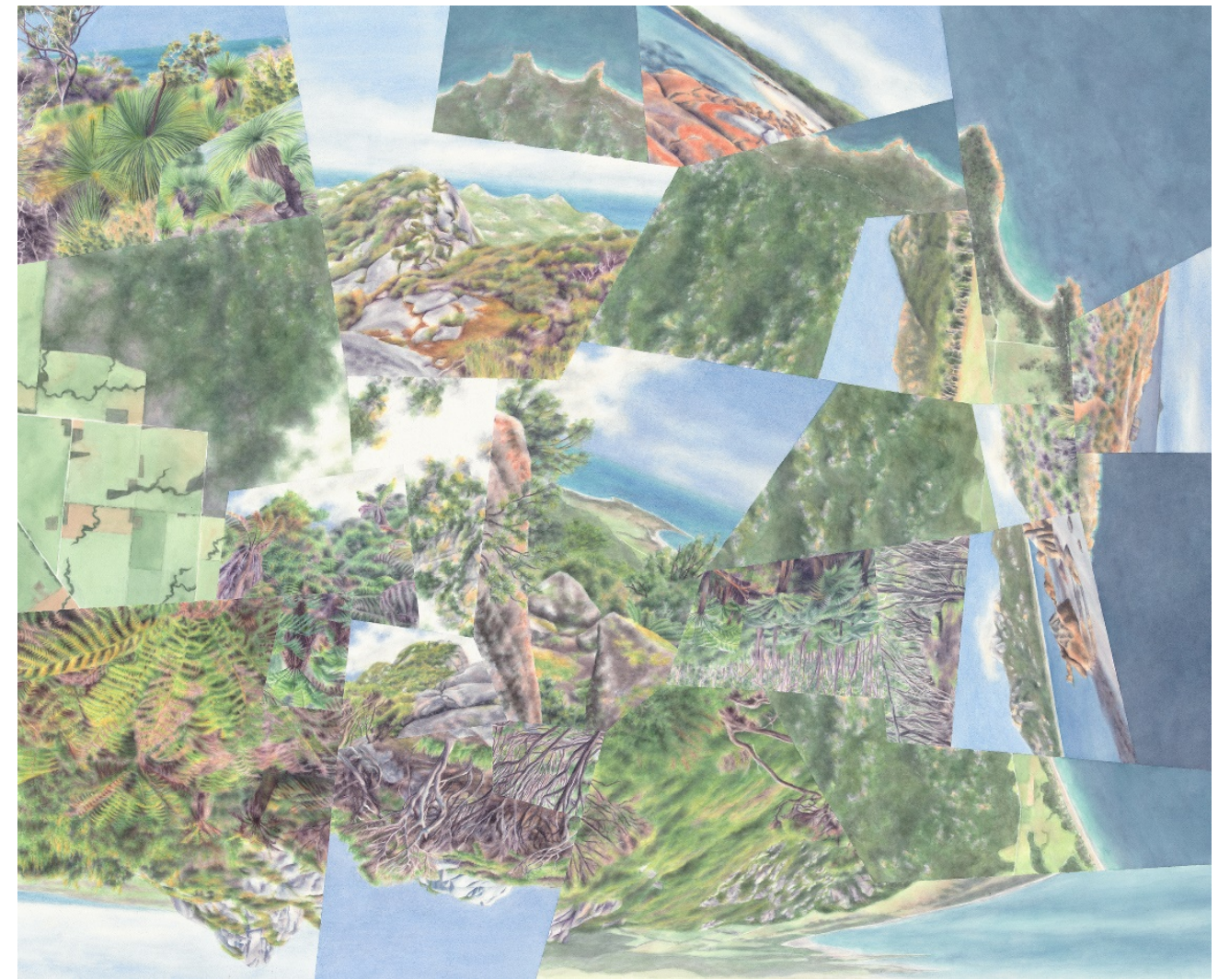

Figure 18. Sanctuary II (watercolor on paper, 36"x44"), capturing the diverse and evocative landscapes of Strzelecki National Park on Flinders Island off the coast of Tasmania. These range from rocky peaks and dry scrublands and forests to pockets of ferny rainforest that are relicts of a wetter age, all squeezed into a corner of the island between ocean and farmland. Taking in the specialness of the place - so close to and yet so far from civilization - and of its many facets gave me the feeling of physically embracing the landscape. That sensation came equally from the knowledge that this small, intricate collection of ecosystems will not easily survive the effects of fire, invasive species, and a warming and drying climate. 